\title{
Diversity Strategies Focused on Employees with a Migration Background: An Empirical Investigation Based on Resource Dependence Theory ${ }^{* *}$
}

In our paper, we develop a typology of diversity strategies through combining elements of strategy research, diversity research, and resource dependence theory. We focus on the question why people with a migration background are (not) employed by organizations. We argue that employment decisions are based on the evaluation of critical resources and the quest to secure their accrual. We identify six diversity strategies, designate each by the importance of respective resources, and derive propositions regarding their relation to competitive strategies. We confront these propositions with empirical data stemming from 500 companies. Correspondence analyses reveal various relationships between diversity and competitive strategies and moderating effects of the company size and the industrial sector. In addition, the robustness of our typology is demonstrated.

Key words: diversity, migration background, employment strategies, resource dependence theory, correspondence analysis

* Renate Ortlieb, Assistant Professor of Human Resource Management, Freie Universität Berlin, School of Business \& Economics, Institute of Management, Boltzmannstr. 20, D - 14195 Berlin, Germany, e-mail: renate.ortlieb@fu-berlin.de.

Barbara Sieben, Assistant Professor of Human Resource Management focused on Diversity, Freie Universität Berlin, School of Business \& Economics, Institute of Management, Boltzmannstr. 20, D - 14195 Berlin, Germany, e-mail: barbara.sieben@fu-berlin.de.

We wish to thank the reviewers for their very helpful comments. The research project, from which this article originates, was granted by the European Social Fund.

** Article received: March 20, 2008

Revised version accepted after double blind review: May 20, 2008. 


\section{Introduction}

In this paper, we use Pfeffer's and Salancik's (1978) resource dependence theory in order to answer the question why people with a migration background are (not) employed in organizations. The perspective on resource dependencies allows us to classify respective resources which may be accrued through their (non)employment and to derive respective diversity strategies. In our theoretical framework, we also build on related concepts of diversity research that describe different approaches to managing diversity. However, for each of these approaches, the respective authors resort to different arguments. For instance, Ely and Thomas (2001) adduce ethical reasons for an emphasis on discrimination and fairness, and a quest for innovation for a perspective on the integration of and learning from diverse employees. In contrast, by building our arguments on resource dependence theory, we are able to give one single, systematic answer to the question why people with a migration background are (not) employed. That is, which diversity strategy is chosen depends on the intent to accrue critical resources and to reduce dependencies from resource providers. We intend to contribute an innovative approach to the research on diversity strategies, particularly those directed toward employees with a migration background.

Nearly two decades ago, Nkomo and Cox (1990) described racial and ethnic minorities as "invisible men and women" in U.S. management research. Whereas Proudford and Nkomo (2006) detect some progress in their overview of research on race in organizations, they also point to open questions, for instance, to the need for studies in non-U.S. contexts. In our research project, from which this paper originates, we focus on personnel structures and practices in German organizations. Here as well, the cultural or ethnic mixture of the workforce has been labeled a "blind spot" in management research (Bissels et al. 2001), and it still may be regarded as such in many respects. Unlike U.S. researchers, who mainly refer to race and ethnicity, in this paper we follow recent German studies and labor market statistics referring to migration background. The concept of migration background broadens the traditional focus on citizenship (and "foreigners") in that it includes also naturalized people, resettlers (ethnic Germans who stem from, for example, Eastern Europe), and their descendents. ${ }^{1}$

In 2005, 15.3 million people with a migration background lived in Germany, representing 18.6 percent of the German population. Among all employees subject to (compulsory) social insurance, 24.4 percent had a migration background. From trends like the demographic change or the globally increasing migration, we may infer that this proportion will rise in the near future.

1 This broadening is crucial if we are interested in the particular situation of racial and ethnic minorities in the German labor force. A focus on citizenship or nationality, for instance, obstructs the view on integration achievements of naturalized people or of second-generation immigrants. The potential disadvantages or discrimination they may suffer also remain unknown. Therefore, official statistics also have used such an extended concept since 2005. As the data show, the group of people with a migration background in Germany is twice as numerous as the group with a foreign nationality. For a more comprehensive discussion of the constraints which result from the (not only) statistically produced limit between "natives" and "foreigners" cf. Beck-Gernsheim (2007). 
In the academic as well as in the public debate, the following two dominant streams form the discourse on people with a migration background: the first discourse stream centers on the problems coinciding with the employment of migrants, as, for example, the research on the former "guest workers" recruited by the Federal Republic of Germany and the corresponding integration problems (Gaugler et al. 1985; Martin 1991; Weber 2004). In contrast, in the second discourse stream, the reason for the employment of people with a migration background, is seen in the additional economic benefit to which these employees may contribute. Primarily in the literature on diversity management, authors emphasize the potential opportunities of an ethnically heterogeneous workforce (see, for example, Cox 1993; Thomas 1996; Richard 2000; Kochan et al. 2003; Horwitz/Horwitz 2007; Krell 2008).

However, the full spectrum of potential reasons for the employment of people with a migration background - or the respective refusal - has not yet been identified. Accordingly, our central research question is: Why are people with a migration background (not) employed in organizations? We embed this question in a broader context, resulting in the question: Which diversity strategies in organizations may be identified?

In this paper, we suggest a typology of diversity strategies based on theoretical considerations, and we confront this typology with empirical data. We thereby also shed light on the configuration of diversity strategies and various context variables.

The paper is organized as follows. First, we sketch out the theoretical framework in which we combine elements of strategy concepts, of approaches stemming from diversity research, and of resource dependence theory. Based on this framework, we generate a classification of resources to be accrued by the employment of people with a migration background and our typology of diversity strategies which we present in the second section. Third, we derive propositions regarding the relation of diversity to competitive strategies. In the subsequent sections, we explicate our empirical approach. We lay out our research design, present, and finally discuss the results of our analyses.

\section{The theoretical framework}

To begin with, we define diversity strategies as particular forms of employment strategies. By this we mean configurations of more or less planned personnel practices as well as the reasons that cause, or are alleged to cause, these practices. We assume that the respective reasons are based on the evaluation of critical resources and the quest to secure their accrual. A diversity strategy thus entails that, in an organization, personnel diversity is produced or excluded and that especially people with a migration background are (not) employed. For this argumentation, we draw on elements of strategy concepts, diversity research, and resource dependence theory. These elements make up the theoretical foundation for our typology of diversity strategies.

\section{Elements of strategy concepts}

First of all, we refer to a rather general notion of strategies as particular patterns of action of relevant organizational members that serve to accomplish long term organizational goals (Grant 2005; Barney 2007). They are shaped by the organizational environment and result from decision processes of individual as well as collective organizational ac- 
tors. Thereby it is critical how top managers (subjectively) evaluate and interpret the situation. Furthermore, strategies are not always planned, but they may also emerge without being intended and be legitimated retrospectively by the organizational actors (Mintzberg 1978; Mintzberg/Waters 1985). More specifically, we understand diversity strategies as particular types of employment strategies (Lutz 1987; cf. also Nienhüser 2007), that is, as the totality of the organizational structures, policies, instruments, and practices that ensure that the organization disposes at acceptable costs of the work force and performance which is needed to realize its global competitive or market strategy.

\section{Elements of diversity research}

In order to derive specific diversity strategies, we fill this general conception of employment strategies with diversity content. For this purpose, we build on corresponding concepts stemming from diversity research, namely, on the following three.

First, we refer to the diversity perspectives identified by Thomas and Ely (1996; Ely/Thomas 2001): discrimination-and-fairness, access-and-legitimacy, and integration-andlearning. According to the authors, these perspectives guide organizational actions and influence how the personnel's diversity affects the efficiency and effectiveness of work. From this conception, we derive specific reasons which may lead organizational decision makers to deal with diversity, and especially to employ people with a migration background.

Second, we build on Janssens' and Zanoni's (2005) findings as to the two service dimensions they distinguish: the norms for producing the service (diversity-customized services, which are planned and rendered with a special regard to the customers' diversity, versus profession-customized services, which follow exclusively technical demands and general professional norms) and the customers' proximity versus their invisibility. According to the authors, these service dimensions affect the organization-specific understanding of diversity and of its management. Against this background, we discern several resources delivered by people with a migration background whose importance depends on the contact with customers.

Third, we draw on the diversity strategies Sackmann et al. (2002) propose based on Cox' (1993) conceptualization of organization models. With regard to our purposes, the special merit of this conception is that it includes such strategies that refer to the nonemployment of people with a migration background. Namely, we refer to the strategies assigned to Cox' model of a monolithic organization with an ideal of homogeneity: the denegation and exclusion of diversity.

These conceptions deliver important aspects for our typology of diversity strategies. However, they are lacking a theoretical foundation. Their empirical basis is also rather scarce: while the latter has not been tested, the former two indeed rely on empirical observations, but these are based on small sample sizes, and both studies were carried out in explicitly diversity-oriented organizations. This is the reason why their findings cannot explain which diversity strategies are applied in organizations and, particularly, why people with a migration background are either employed or not employed. Thus, we add to our theoretical framework, as a final and at the same time central element, reflections on the resource dependence of organizations according to Pfeffer and Salancik (1978). 


\section{Elements of resource dependence theory}

With regard to resource dependence theory, we build on the core argument of Pfeffer and Salancik (1978) that organizations establish exchange relations with actors in their external environment because they are in need of resources like capital, knowledge, or technologies. As a result, the organization is dependent on these actors. As is known, the strength of this dependence is based on the importance and criticality of resources for the organization, on the extent of the resource control by other actors, and on its concentration, that is, the alternatives an organization has to obtain a certain resource. Thus, organizational strategies derive from the quest to secure the accrual of resources permanently and from the intent to reduce the dependence on other actors at the same time.

Pfeffer and Salancik (1978) focus particularly on other organizations as exchange partners, and they discuss primarily organizational strategies like diversification or vertical integration. However, their approach has often been expanded to individual external actors, to internal actors, and to employment strategies (see Pfeffer/Cohen 1984; Pfeffer/Davis-Blake 1987; Milliken et al. 1998; Baker/Aldrich 1999; Nienhüser 2007). These analyses show that the employer's dependence on employees who control critical resources enables these employees to negotiate better working conditions or salaries.

For our theoretical framework, we draw corresponding arguments from a resource dependence perspective. In line with our main question - why people with a migration background are (not) employed in organizations - we focus particularly on the initial act of recruiting and the appointment of jobs. We assume thereby that at the core their (non)employment serves to reduce dependencies on external critical resources. Relevant organizational actors will choose such diversity strategies that are evaluated as being the most adequate for the accrual of resources. This evaluation in turn depends on the appraisal of resources, that is, the questions of which resources are actually regarded as critical and which ones count as scarce in the organization or its environment. Our focus lies on these evaluation processes and their outcomes in terms of the (non)employment of people with a migration background. What reasons do organizational actors allege for hiring them? Are they considered to control critical resources, be it in terms of the possession of them (e.g., of language skills) or the possibility to gain access to them (e.g., to detailed information about a country)? Are they employed to ensure the accrual of other resources, e.g., financial resources stemming from clients or sponsors? Is their employment in other cases thought to prevent the accrual of such resources? In this sense, we aim at developing the resource concept. With a special regard to the employment of people with a migration background, we differentiate, specify, and classify related resources, and we illustrate how tightly internal and external resources are coupled. This in turn builds the basis for our typology of diversity strategies presented in the next section.

\section{A typology of diversity strategies}

In the following, we present the typology of diversity strategies which we derived from our theoretical framework. As discussed earlier, we differentiate diversity strategies by the "good reasons" organizational decision makers allege for the (non)employment of people with a migration background. Furthermore, we presume 
that these reasons will regularly build on the appraisal of resources and on reflections on how the accrual of resources may be ensured. Following Mintzberg (1978), we take into account that such reasoning may happen either ex ante or ex post, and that people with a migration background may also (not) be employed without particular "good reasons".

In sum, our typology consists of six diversity strategies that we named Antidiscrimination, Adding value through migration background, Adding value through mere labor, Learning, Exclusion, and Hazard. We generated the typology by reinterpreting the elements of diversity research described above out of a resource dependence perspective (Ortlieb/Sieben 2008). This reinterpretation allows us to classify different types of resources whose accrual may be ensured by the employment of people with a migration background and to discern corresponding diversity strategies.

Table 1 contains a synopsis of relevant resources, classified by the sources from which they stem. Organizational decision makers may aim at gaining resources that are under control and in possession of people with a migration background. On the other hand, through the accrual of such resources, they also aim at attaining resources stemming from further stakeholders and different markets.

Table 1: Types of resources whose accrual is intended to ensure by the employment of people with a migration background

\begin{tabular}{|c|c|c|}
\hline \multicolumn{3}{|c|}{ Resources controlled by people with a migration background } \\
\hline \multirow[t]{5}{*}{ Qualifications } & & related to the migration background \\
\hline & & - language skills \\
\hline & & - cultural skills and knowledge \\
\hline & & - new perspectives and approaches to work tasks \\
\hline & - & not related to the migration background \\
\hline \multirow[t]{2}{*}{ Mere labor } & - & readiness to work for a low wage \\
\hline & - & $\begin{array}{l}\text { readiness to work in undesired jobs (e.g., due to high strain, lacking career } \\
\text { prospects, low reputation) }\end{array}$ \\
\hline \multicolumn{3}{|c|}{ Migration background itself (e.g., as a sign for authenticity or internationality) } \\
\hline$\downarrow$ & \multicolumn{2}{|c|}{ lead to the accrual of } \\
\hline \multicolumn{3}{|c|}{ Resources stemming from other sources } \\
\hline \multirow[t]{2}{*}{ Labor market resources } & & $\begin{array}{l}\text { new personnel (e.g., through network recruiting, through the image as an } \\
\text { employer that obeys fairness dictates and discrimination prohibitions) }\end{array}$ \\
\hline & - & work performance of existing personnel with a migration background \\
\hline \multirow[t]{2}{*}{ Consumer market resources } & & $\begin{array}{l}\text { purchases or orders by governmental and private clients who expect that fairness } \\
\text { dictates and discrimination prohibitions are obeyed }\end{array}$ \\
\hline & - & $\begin{array}{l}\text { purchases or orders by clients who expect that persons with a special migration } \\
\text { background are employed (e.g., because they have the same migration } \\
\text { background or because they value the migration background as a sign for the } \\
\text { authenticity of the product) }\end{array}$ \\
\hline Financial market resources & & $\begin{array}{l}\text { capital given by investors (e.g., shareholders or creditors) who expect that } \\
\text { fairness dictates and discrimination prohibitions are obeyed }\end{array}$ \\
\hline
\end{tabular}


Based on this classification, we characterize the six diversity strategies by the type and the importance of resources controlled by people with a migration background. By "importance" we refer to the different aspects that Pfeffer and Salancik (1978) name: the relative scope of required resources, their criticality, as well as the possibility to obtain the resources through alternative sources. Table 2 summarizes the respective profile of the diversity strategies by the importance of resources. The strategies are entered in the columns; the types of resources are listed in the rows. In the resulting cells, we indicate how important a resource is for the respective strategy.

Table 2: Diversity strategies by the importance of resources to be accrued

\begin{tabular}{|c|c|c|c|c|c|c|c|}
\hline \multirow{2}{*}{\multicolumn{2}{|c|}{$\begin{array}{l}\text { Resources controlled by } \\
\text { people with a migration } \\
\text { background }\end{array}$}} & \multicolumn{6}{|c|}{ Diversity strategy } \\
\hline & & \multirow[t]{2}{*}{$\begin{array}{l}\text { Anti- } \\
\text { discrimina- } \\
\text { tion }\end{array}$} & \multirow[t]{2}{*}{$\begin{array}{l}\text { Adding value } \\
\text { through } \\
\text { migration } \\
\text { background }\end{array}$} & \multirow[t]{2}{*}{$\begin{array}{l}\text { Adding } \\
\text { value } \\
\text { through } \\
\text { mere labor }\end{array}$} & \multirow[t]{2}{*}{ Learning } & \multirow[t]{2}{*}{ Exclusion } & \multirow[t]{2}{*}{ Hazard } \\
\hline \multirow[t]{3}{*}{-} & Qualifications & & & & & & \\
\hline & $\begin{array}{l}\text { - related to } \\
\text { migration } \\
\text { background }\end{array}$ & $\begin{array}{l}\text { not } \\
\text { important }\end{array}$ & $\begin{array}{l}\text { very } \\
\text { important }\end{array}$ & $\begin{array}{l}\text { not } \\
\text { important }\end{array}$ & $\begin{array}{l}\text { very } \\
\text { important }\end{array}$ & $\begin{array}{l}\text { not } \\
\text { important }\end{array}$ & $\begin{array}{l}\text { not } \\
\text { important }\end{array}$ \\
\hline & $\begin{array}{l}\text { - } \text { not related to } \\
\text { migration } \\
\text { background } \\
\end{array}$ & $\begin{array}{l}\text { very } \\
\text { important }\end{array}$ & $\begin{array}{l}\text { perhaps } \\
\text { important }\end{array}$ & $\begin{array}{l}\text { perhaps } \\
\text { important }\end{array}$ & important & $\begin{array}{l}\text { not } \\
\text { important }\end{array}$ & $\begin{array}{l}\text { perhaps } \\
\text { important }\end{array}$ \\
\hline \multirow[t]{3}{*}{-} & Mere labor & & & & & & \\
\hline & - low wages & $\begin{array}{l}\text { not } \\
\text { important }\end{array}$ & $\begin{array}{l}\text { not } \\
\text { important }\end{array}$ & $\begin{array}{l}\text { very } \\
\text { important }\end{array}$ & $\begin{array}{l}\text { not } \\
\text { important }\end{array}$ & $\begin{array}{l}\text { not } \\
\text { important }\end{array}$ & $\begin{array}{l}\text { not } \\
\text { important }\end{array}$ \\
\hline & - undesired jobs & $\begin{array}{l}\text { not } \\
\text { important }\end{array}$ & $\begin{array}{l}\text { not } \\
\text { important }\end{array}$ & $\begin{array}{l}\text { very } \\
\text { important }\end{array}$ & $\begin{array}{l}\text { not } \\
\text { important }\end{array}$ & $\begin{array}{l}\text { not } \\
\text { important }\end{array}$ & $\begin{array}{l}\text { not } \\
\text { important }\end{array}$ \\
\hline- & $\begin{array}{l}\text { Migration background } \\
\text { itself }\end{array}$ & $\begin{array}{l}\text { perhaps } \\
\text { important }\end{array}$ & $\begin{array}{l}\text { very } \\
\text { important }\end{array}$ & $\begin{array}{l}\text { not } \\
\text { important }\end{array}$ & $\begin{array}{l}\text { not } \\
\text { important }\end{array}$ & $\begin{array}{l}\text { not } \\
\text { important }\end{array}$ & $\begin{array}{l}\text { not } \\
\text { important }\end{array}$ \\
\hline
\end{tabular}

As mentioned before, some of these strategies resemble those derived by Ely and Thomas (2001) as well as those derived by other authors. But this differentiation goes far beyond by drawing on a resource dependence perspective. The following aspects are essential in this regard.

The strategy of Anti-discrimination is not only pursued on moral grounds, as Thomas and Ely postulate. Rather, by implementing personnel practices directed to equal opportunities, organizational actors aim at ensuring access to resources which they evaluate as important. This may contribute to winning the best qualified employees free from filtration through discriminating practices. With a special regard to resources stemming from other sources, the access to resources from clients and investors may also provide "good reasons" for this strategy, whenever these stakeholders are known to expect that equal opportunities practices are demonstrated. Corresponding practices are equally essential for the following strategies that aim at the employment of people with a migration background. However, we distinguish this "mere" antidiscrimination quest from the other strategies in that resources related to the migration background of (potential) employees are not regarded as particularly important. Rather, this strategy is to ensure that qualifications and expertise from all (potential) employees, including those pertaining to traditionally underrepresented groups, are 
obtained. Yet, one further type of resource controlled by people with a migration background may be important. The migration background itself may be evaluated as critical, as it may function as a signal that equal opportunities prevail in the organization.

The peculiarity of the strategy Adding value through migration background is that organizational decision makers regard qualifications related to a migration background as notably important. Be it language, cultural skills, or the migration background itself, such attributes are valued as critical resources for delivering services and for gaining access especially to consumer markets. As a consequence, other qualifications of these employees may also turn into critical resources, virtually in those cases in which qualified jobs are concerned.

For the strategy Adding value through mere labor, the mere working capacity of people with a migration background is of salient importance. Neither the migration background itself nor qualifications related to it turn into critical resources. People with a migration background are employed whenever they are ready to work for low wages or to execute undesired jobs. If certain technical qualifications are needed for such jobs, these may also turn into important resources.

The strategy Learning is characterized by the preeminent importance of one specific resource controlled by people with a migration background, namely, new perspectives and approaches to work. These are regarded as essential for process and product innovations. As jobs in which employees are enabled to contribute to such innovations are regularly qualified ones, other qualifications of these people may also turn into critical resources. In this sense, Learning is also a strategy which aims at adding value through the employment of people with a migration background. But in contrast to the strategies mentioned above, neither their mere labor nor the migration background itself is considered important, but rather their ways of handling problems and finding solutions. This implies at the same time that personnel practices aim at constituting and preserving a heterogeneous workforce, for it is the mixture of perspectives and approaches to work which is thought to yield synergetic effects and is valued as a prerequisite for organizational learning.

Constitutive for the strategy of Exclusion is that no people with a migration background are employed. In this case, organizational decision makers regard none of the resources whose accrual may be ensured by their employment as important. Moreover, some of these potential resources will be considered undesirable, as they may in the judgment of the organizational decision makers - be dysfunctional for the accrual of resources from the different markets. Reasons may be that investors or clients are considered to expect personnel without a migration background. Disturbances in the co-operation of the existing personnel without a migration background may also be anticipated. In other words, the nonemployment of people with a migration background is, in this case, to ensure the performance of other employees.

For the strategy Hazard, again, none of the potential resources are evaluated as important. People with a migration background are either employed or not employed; in neither case do organizational decision makers attribute specific reasons to this 
fact. $^{2}$ Solely those qualifications independent of a migration background may be a reason for the (non)employment of people with a migration background, as organizational decision makers strictly focus the job requirements and the aptitude of potential employees irrespective of their migration background. However, in contrast to the strategy Anti-discrimination, qualifications will typically not be regarded as scarce and their accrual as of particular importance, for this would imply a reflection on how to attract employees with diverse backgrounds. Also, it simply doesn't matter if the composition of the workforce enables the accrual of resources from other sources or not.

To sum up, all six diversity strategies rest on evaluations of the criticality of resources. These theoretical reflections lead to our first proposition to be confronted with our empirical data:

Proposition 1: The six theoretically constructed diversity strategies - Anti-discrimination, Adding value through migration background, Adding value through mere labor, Learning, Exclusion, and Hazard - do exist.

Note that we speak here and in the following of propositions instead of hypotheses, as our approach is of rather exploratory nature. Rather than to specify detailed hypotheses, we formulate coarser propositions and rely on their guiding function to explore the field of the employment of people with a migration background. In order to achieve deeper insight into the choice and emergence of diversity strategies, we now turn to their relation to competitive strategies.

\section{The relation to competitive strategies}

A look at the organization's context helps to further approach the question of why organizations do (not) employ people with a migration background and the corresponding question of why organizations pursue which diversity strategy. Our main focus here is on competitive strategies, because they typically co-determine which resources are regarded as critical for the organization (Lutz 1987; Schuler/Jackson 1995; Nienhüser 2007). Hence, we suppose that an organization's competitive strategy will be closely related to the choice or emergence of a diversity strategy. We build on the generic strategies differentiated by Porter (1980): cost leadership, which requires seeking for cost reductions as to all input factors and business processes; differentiation strategy, which involves striving for high quality, innovative processes and products; and focus strategy, which is characterized by the concentration on a specific niche. Let us first discuss which competitive strategies will presumably coincide with specific diversity strategies. After that, we will proceed to further contextual factors which we assume to affect this relation.

For instance, because a cost leadership strategy implies the quest for low labor costs, we expect this strategy to coincide especially with the diversity strategy Adding

2 Note that the previous five strategies are constituted by both the fact of the (non)employment of people with a migration background and the respective reasoning of organizational decision makers. In contrast, for the strategy Hazard, their factual (non)employment is irrelevant. Here, the main point is the lack of specific reasoning and maybe even the lack of recognizing the individual characteristic of having a migration background. 
value through mere labor. In contrast, pursuing a differentiation strategy with its focus on high quality and innovation requires above all highly qualified employees. Therefore it may be associated with the strategies Anti-discrimination, Adding value through migration background and Learning - i.e., those strategies that are suitable for the attraction and retention of highly qualified employees. Regarding a focus strategy, the corresponding diversity strategy depends on the target market or the community whose needs are to be met. For example, if a university located outside Asia offers an MBA degree program with an emphasis on Asian markets and culture, this university may employ faculty members with an Asian background, thus pursuing the strategy Adding value through migration background. Furthermore, a focus strategy may coincide with this diversity strategy if the niche is characterized by customers with a migration background. If the target market, however, represents a segment of domestic cutomers without a migration background, the focus strategy implies a diversity strategy of Exclusion. The following set of propositions condenses these considerations. Note that we thereby omit the strategy Hazard. Because arbitrariness is the very essence of this strategy, it implies no certain relationship of this kind.

Proposition 2: Diversity strategies are empirically related to competitive strategies.

Proposition 2a: A cost leadership strategy corresponds to the diversity strategy Adding value through mere labor.

Proposition 2b: A differentiation strategy corresponds to the strategies Antidiscrimination, Adding value through migration background or Learning.

Proposition 2c: A focus strategy corresponds either to Adding value through migration background or Exclusion.

Furthermore, we assume that the relation of diversity strategies and competitive strategies is moderated by various factors, two of which we inspect in the following: the organization's size and the industrial sector. The organization size, i.e., the number of employees, implies different degrees of both intention and realizability of diversity strategies. Large companies typically dispose of a human resources department and executives on different hierarchical levels. This makes the strategic planning and pursuit of personnel practices more probable. In addition, the fact that large companies are under tighter public observation will force them more than small companies to gain legitimacy and credibility on the part of consumers and creditors. Accordingly, our third proposition is:

Proposition 3: The company size will moderate the relationship between diversity and competitive strategies.

Note that, with regard to the moderating effect of the company size, we refrain from generating more detailed propositions as we have done for proposition 2. The reason is that we are not able to specify on theoretical grounds the size's mode of action on the relationships between the diversity strategies and the competitive strategies.

Finally, we propose that the industrial sector also has a moderating effect. First, some branches provide a relatively high proportion of job tasks characterized by high physical strain, a low level of skill demand, and low salaries, e.g., cleaning companies and industrial manufacturers. Second, some branches explicitly build on international 
business, e.g., tourism organizations, some cultural industry organizations, and international trade companies. Such branch characteristics will affect the choice and emergence of both competitive and personnel strategies. Nevertheless, analagous to the moderating effect of the company size, we are not able to conjecture theoretically in which way the industrial sector will have a bearing on their relationship. Hence, our last proposition reads as follows:

Proposition 4: The industrial sector will moderate the relationship between diversity and competitive strategies.

Subsequently we explicate the design of our empirical approach. Then we present the results of the respective data analyses as to the existence of diversity stategies and their relation to competitive strategies.

\section{Research design}

\section{Sample}

For our empirical examination, we collected data in the autumn of 2007 by standardized, fully structured telephone interviews with heads of personnel of 500 companies in a large German city. The sample is stratified by company size (built on the number of employees) and by industrial sector, as shown in table 3. Regarding industrial sector, the stratification is proportional to the whole population. Regarding company size, we sampled disproportionately in order to increase the number of large companies. This is because we wanted to gain insight into large companies, which are very rare in the considered population. Within the cells the companies were chosen randomly.

\section{Table 3: Sampling}

\begin{tabular}{|c|c|c|c|c|}
\hline \multirow[b]{2}{*}{ Sector (NACE-code) } & \multicolumn{4}{|c|}{ Number of employees } \\
\hline & $5-50$ & $51-200$ & $>200$ & Total \\
\hline $\begin{array}{l}\text { Manufacturing, energy/water and construction } \\
(D, E, F)\end{array}$ & 52 (15\%) & $9(12 \%)$ & 10 (14 \%) & 71 (14 \%) \\
\hline $\begin{array}{l}\text { Trade and hotels/restaurants } \\
(\mathrm{G}, \mathrm{H})\end{array}$ & $88(25 \%)$ & $13(17 \%)$ & $7(10 \%)$ & $108(22 \%)$ \\
\hline $\begin{array}{l}\text { Further services } \\
(\mathrm{I}, \mathrm{J}, \mathrm{K}, \mathrm{L}, \mathrm{N}, \mathrm{O})\end{array}$ & $210(60 \%)$ & $56(72 \%)$ & 55 (76 \%) & $321(64 \%)$ \\
\hline Total & $350(100 \%)$ & 78 (100\%) & $72(100 \%)$ & $500(100 \%)$ \\
\hline
\end{tabular}

\section{Measures}

The size of the company (based on the number of employees) and the industrial sector to which it is affiliated stem from the database used for sampling. All further constructs were measured through one or more questions in the telephone interviews.

In order to measure the proportion of employees with a migration background in the total workforce, the interviewer first gave the definition of people with a migration background outlined above, followed by the open question, "If you estimate it roughly: 
what percentage does the proportion of employees with a migration background amount to in your organization?".

As to measuring the resources to be accrued by the (non)employment of people with a migration background, interviewees were asked to indicate the reasons why they employ these people or refuse to do so, respectively. We developed the single items for these questions closely to the concepts explained above. Table 4 gives an outline of these measures. Building on the items regarding the preferableness of people with a migration background (item 5. a-k), "non-employers" were also asked if they could imagine these reasons becoming relevant for them in the future.

Table 4: Measures of the resources to be accrued by the (non)employment of people with a migration background

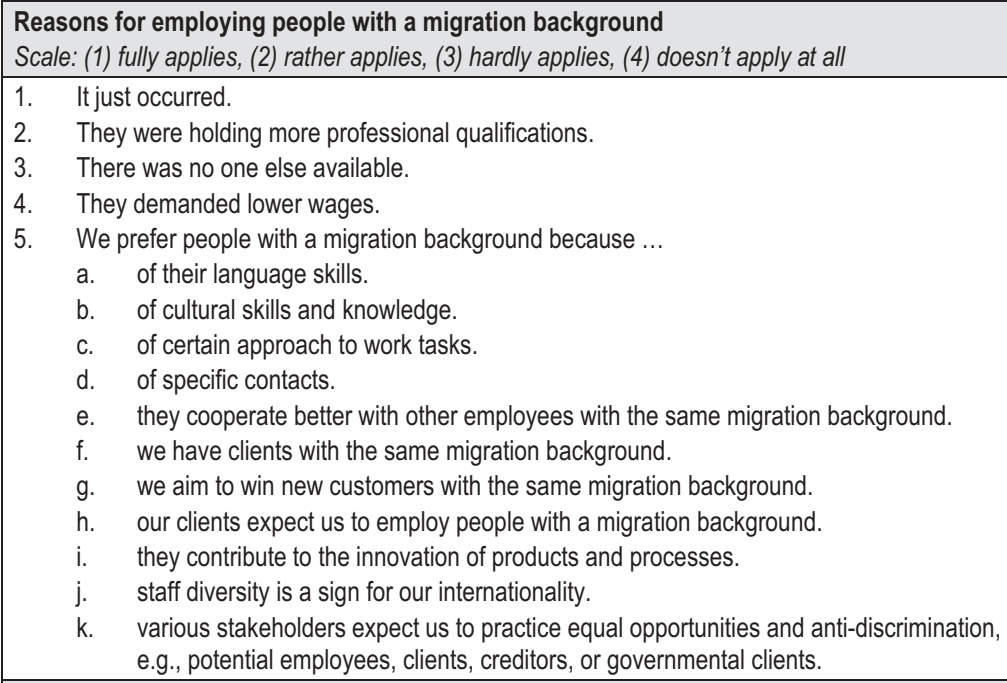

Based on these resource-oriented measures, we categorized the companies as pursuing one of the diversity strategies elaborated above. To classify a company as pursuing the strategy Anti-discrimination, the following conditions had to be met: at least one person with a migration background is employed. Of the reasons listed in table 4, the interviewee states neither availability (3.) nor lower wage claims (4.) to apply. Instead, she/he rates professional qualifications (2.) highly. Specific resources tied to the migration background of employees or customers (5. a-i) are not of special importance. However, the signaling of internationality (5.j) and the expectations of different stakeholders that equal opportunities and anti-discrimination are practiced (5. k) are stated to apply. 
To be categorized as pursuing the strategy Adding value through migration background, again, at least one person with a migration background must be employed, and the interviewee neither states availability (3.) nor lower wage claims (4.) to apply. But now, at least one of the reasons as to specific resources tied to the migration background of employees or customers is of special importance (5. a-h). However, the contribution to the innovation of products and processes (5. i) is not stated to apply.

To count as pursuing the strategy Adding value through mere labor, again at least one person with a migration background should be employed in the company. As a reason for this, the interviewee states either availability (3.) or lower wage claims (4.) to apply.

For the strategy Learning, at least one person with a migration background should be employed as well. The interviewee resorts thereby neither to availability (3.) nor to lower wage claims (4.). From the spectrum of specific reasons related to the migration background, especially the contribution to the innovation of products and processes (5. i) must apply.

The strategy Exclusion is constructed as follows: the proportion of employees with a migration background does not exceed 5 percent. As a reason for this, the interviewee either states that the company fosters homogeneity (9.) or that customers expect not to be served by persons with a migration background (10.).

As to the strategy Hazard, we built a two-fold construction depending on if people with a migration background are employed. If at least one person is employed, the interviewee must state neither availability (3.) nor lower wage claims (4.) nor other specific reasons (5.) to apply. Rather, she/he states that it just occurred (1.). If no people with a migration background are employed, the interviewee must also resort to an incidental occurrence (6.). Moreover, the interviewee must neither state that the company fosters homogeneity (9.) nor that customers expect not to be served by people with a migration background (10.).

A further measure refers to the competitive strategy in the sense of Porter (1980) which is pursued by the organization. In this regard, interviewees were asked in how far the statements listed in table 5 applied.

Table 5: Measures of the competitive strategy pursued

\section{Competitive strategy}

Scale: (1) fully applies, (2) rather applies, (3) hardly applies, (4) doesn't apply at all

1. Compared to our competitors, we strive to keep costs as low as possible.

2. Compared to our competitors, we strive to offer innovative, "unique" products and services.

3. We strive to assert our position in a market niche, if possible without competitors.

\section{Methods}

We deploy different methods in our analyses. According to the character of our propositions, we pay particular attention to a visual inspection of the data. First, in order to investigate the existence of the six diversity strategies, we draw on the univariate frequency distribution. To inspect the relation of diversity to competitive strategies, we then apply correspondence analysis. We complement the visual inspection of the correspondence analyses maps by analyses of contingency tables. Finally, to get 
further insight into the relationships proposed, we estimate multinomial and binary logistic regression models. All analyses were carried out with SPSS 15.0.

\section{Results}

We present the results of our data analyses in the following. We proceed by separately investigating the four propositions derived above. To complete the presentation of results, we finally comment on further steps of analysis which we carried out in order to examine our typology of diversity strategies and their relation to competitive strategies.

\section{Proposition 1: Existence of the six diversity strategies}

Based on our empirical data, we first aimed at identifying the diversity strategies we derived from our theoretical considerations. Figure 1 displays the frequency distribution of the diversity strategies. It shows that we succeeded in observing all six diversity strategies. Hence, proposition 1 is supported.

Figure 1: Frequency distribution of the diversity strategies

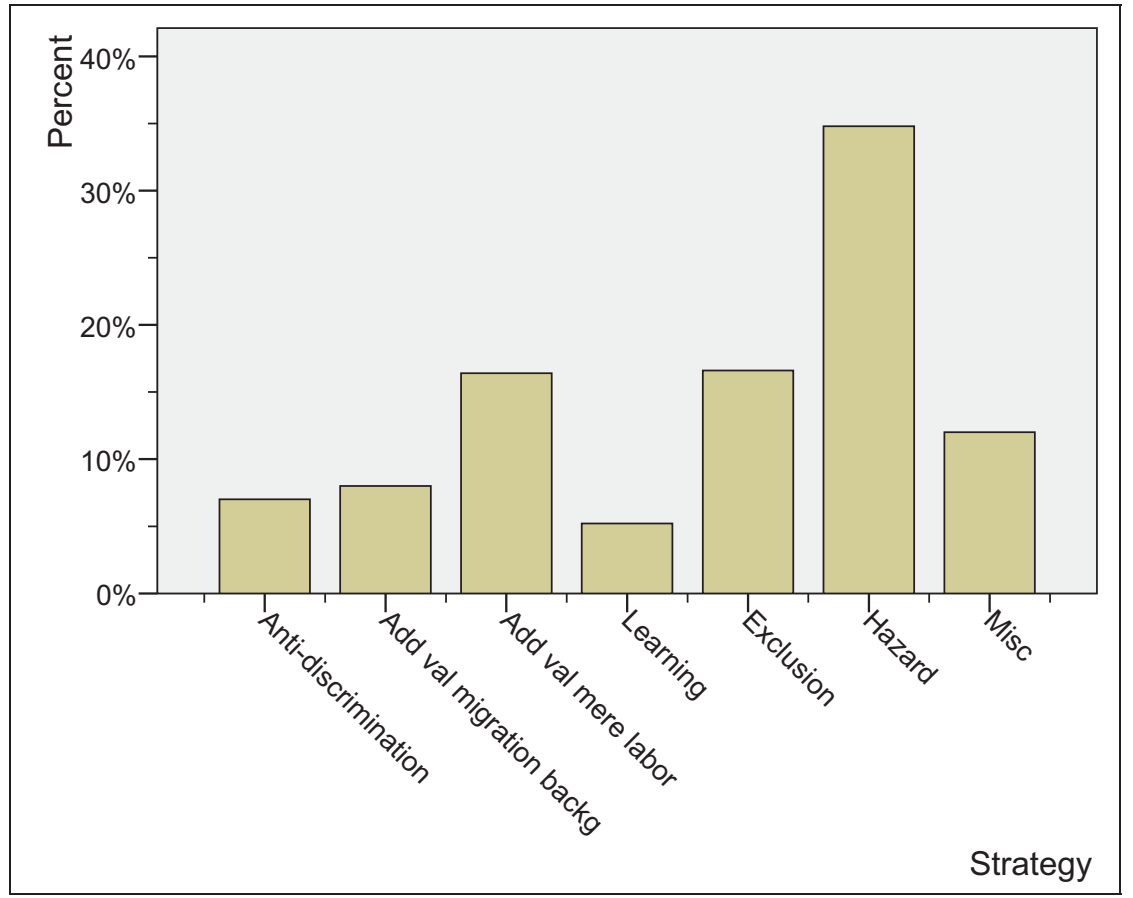

The most prevalent strategy is Hazard. Among the investigated companies, 174 $(34.8 \%)$ were categorized as (not) employing people with a migration background without specific reasons. With $26(5.2 \%)$ of the considered companies, Learning is the strategy pursued most seldom. We classified $35(7.0 \%)$ companies as pursuing the strategy Anti-discrimination and $40(8.0 \%)$ companies as pursuing Adding value through migration background. Finally, with $82(16.4 \%)$ and $83(16.6 \%)$ companies respectively, the prevalence of the strategies Adding value through mere labor and Exclusion is quite 
similar. Note that after our classification procedure, $60(12.0 \%)$ companies remained unclassified. That means these companies met only some of the outlined conditions but failed to do so regarding others. We have named this category Miscellaneous.

\section{Proposition 2: Relationship between diversity strategies and competitive strategies}

To investigate proposition 2, we applied a correspondence analysis. This data analysis technique is especially well suited for the graphical mapping of associations between nominal scaled variables and their categories. On the basis of contingency tables, twodimensional maps representing both rows and columns in a joint space are created (Benzécri 1992; Greenacre/Blasius 1994; Hair et al. 2006; Nenadić 2007). The respective map is displayed in figure 2. Note that we have omitted the strategies Hazard and Miscellaneous because of their arbitrariness.

Figure 2: Correspondence analysis map of the diversity strategies in relation to the competitive strategies

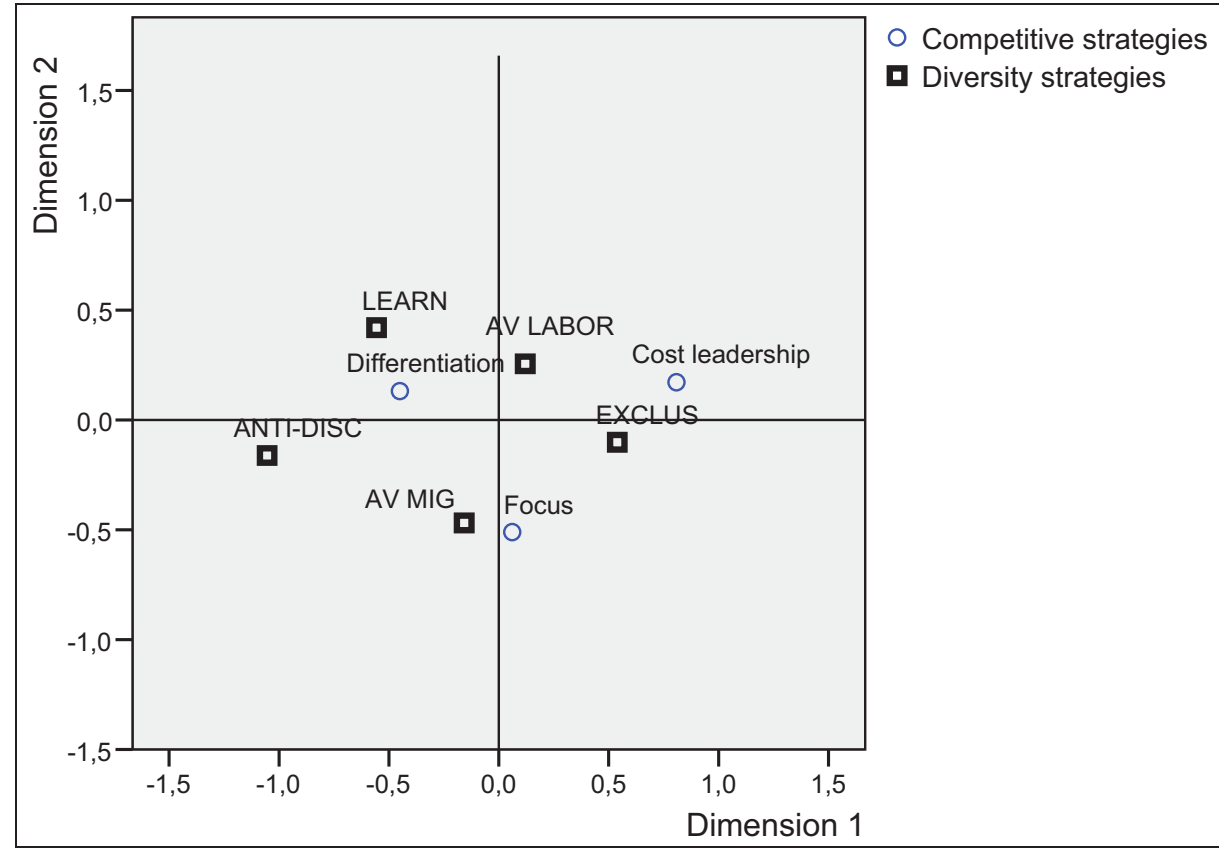

Notes: $\quad \mathrm{N}=239$; plot is based on $\mathrm{Chi}^{2}$-distances and symmetric normalization;

Diversity strategies: ANTI-DISC = Anti-discrimination, AV MIG = Adding value through migration background, $\mathrm{AV} L \mathrm{LBOR}=$ Adding value through mere labor, LEARN = Learning, EXCLUS = Exclusion

To identify corresponding strategies - that is, combinations of one diversity strategy and one competitive strategy that are frequently observed - in figure 2 , one searches for points at close range. ${ }^{3}$ Starting with the point representing the competitive strategy

3 It is a controversial issue whether the distance between two points may be interpreted directly as an association, if one of the points represents a category of one variable (e.g., the 
cost leadership (proposition 2a), we find the diversity strategies Exclusion and - as expected - Adding value through mere labor to be nearby. However, the latter is close to the competitive strategy differentiation as well (proposition 2b). A differentiation strategy is most strongly related to the diversity strategy Learning and also to Anti-discrimination. Whereas we proposed these relationships, the other presumed relation to the diversity strategy Adding value through migration background cannot be identified. Finally, as presumed, the point representing the competitive strategy focus (proposition 2c) is immediately next to that representing the diversity strategy Adding value through migration background. However, the point representing the strategy Exclusion is comparatively far away. To sum up, the majority of the relationships our propositions $2 \mathrm{a}$ to $2 \mathrm{c}$ deal with can be preliminarily supported.

Correspondence analysis not only aims at the identification of associated variables and categories, but also at the detection and interpretation of latent structures in the data. For this purpose, one regards the contribution of each single point to what is termed the inertia accounted for by the respective axis. ${ }^{4}$ However, as we are essentially interested in those diversity strategies derived from our theoretical considerations, we only briefly look at the two dimensions that generate the biplot: dimension 1 is more "important" than dimension 2, as it accounts for $93.3 \%$ of the total variance. It is shaped by the diversity strategies as they spread above all over this dimension. Thus, dimension 1 clearly mirrors the degree to which people with a migration background are integrated into companies and the degree to which organizational decision makers ascribe unique qualifications or individual characteristics to them. The interpretation of dimension 2 is more difficult. But as it accounts for only $6.7 \%$ of the total variance, we can leave this question open without damage.

In order to enhance the power of our analyses, we looked at the contingency table that underlies the map in figure 2 to complement our visual inspection of the plot. $^{5}$ As a whole, the relation between diversity and competitive strategies is significant $\left(\mathrm{p}<0.05\right.$; Pearson's $\mathrm{Ch}^{2}=19.95 ; 8$ degrees of freedom). This means proposition 2 is supported. To assess the propositions $2 \mathrm{a}$ to $2 \mathrm{c}$, we compared every single cell

row-variable in a two-way contingency table) and another point represents a category of the other variable (the column-variable). Whereas Greenacre states that " $[\mathrm{t}]$ here is no direct row-to-column interpretation” (1994: 21), Benzécri (e.g., 1992: 421) indeed suggests a joint interpretation. Beyond dispute is the way of indirect interpretation. In this case, one looks at the position of the points with respect to the center of a configuration, i.e., the origin of the plot. However, because the procedure of indirect interpretation reveals largely the same results as the direct interpretation with the cost of a loop way, in the following we always interpret the points' distances directly as an association of the respective diversity and competitive strategy.

4 This procedure is similar to factor analysis: the inertia of an axis is equivalent to the eigenvalue of a factor. However, whereas in factor analysis the construction of the axes is usually based on Euclidean distances, in correspondence analysis it usually rests on $\mathrm{Chi}^{2}$ distances (which are weighted Euclidean distances).

5 Due to space restrictions, neither the contingency tables nor the sensitivity analysis results of this and all subsequent propositions are included in the article. They are available from the authors on request. 
percentage with the respective marginal frequency, that is, the total percentage in the same row. A substantive deviation between these percentages - to count as substantive we decided that the cell percentage must be at least 1.2 times as large as the marginal percentage of the respective row - should indicate support of the proposition. The results exactly confirmed our visual impressions described above. Furthermore, we conducted sensitivity analyses with randomly chosen subsamples, starting with $50 \%$ of the total sample size and increasing that four times in steps by $10 \%$. The generated maps turned out to be very similar, which indicates stable results.

Summing up, we may say that all of our propositions regarding the bivariate relationship between the diversity strategies and the competitive strategies are supported by our empirical analyses. One exception is the diversity strategy Exclusion, which had been suggested to correspond to a focus strategy but proved to correspond to a cost leadership strategy.

\section{Proposition 3: Moderating effect of the company size}

Now we extend the analysis in a multivariate direction. Again, in an initial step we carried out a correspondence analysis. For this purpose, we added the company size to the bivariate relationships between diversity and competitive strategies. The resulting map of this multiple correspondence analysis is presented in figure 3.

Figure 3: Multiple correspondence analysis map - moderating effect of the company size (number of employees)

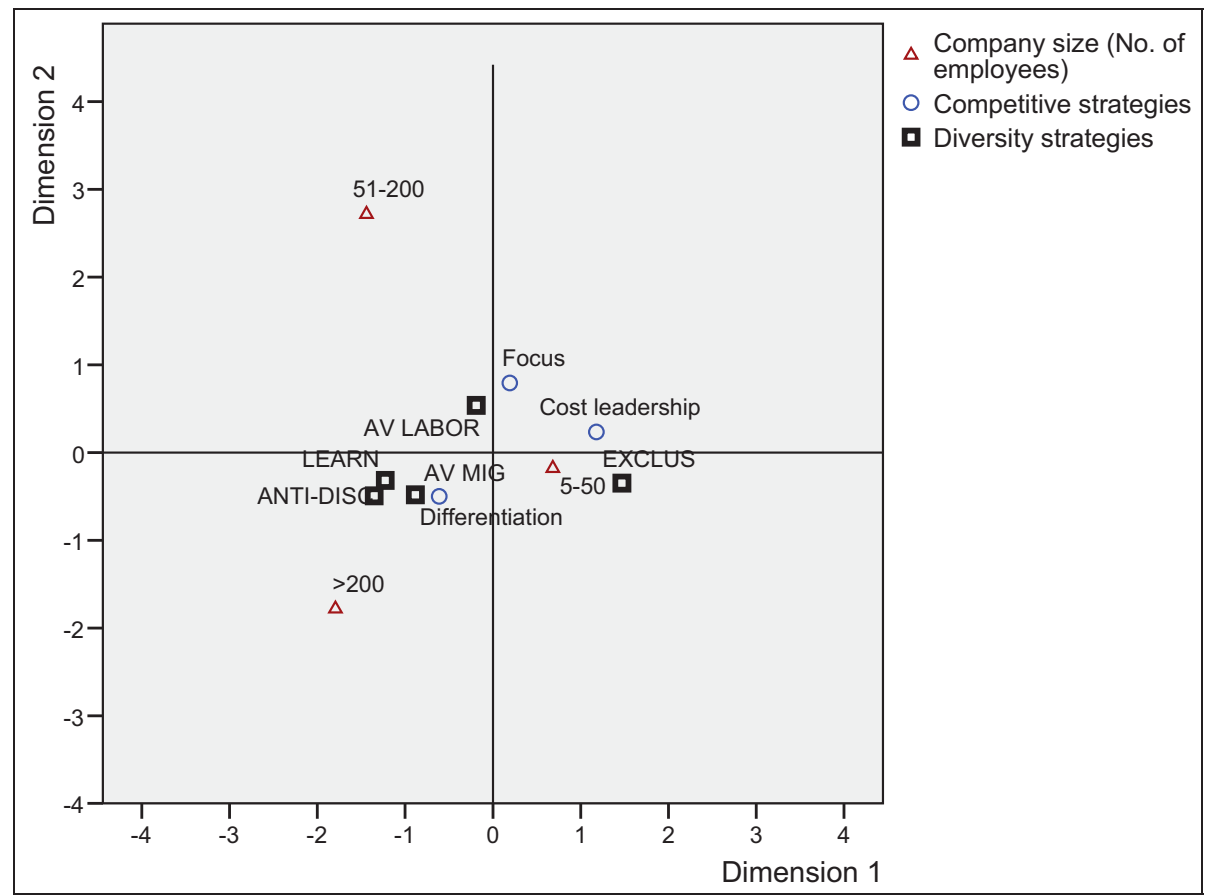

Notes: $\quad \mathrm{N}=239$; plot is based on Chi²-distances and symmetric normalization;

Diversity strategies: ANTI-DISC = Anti-discrimination, AV MIG = Adding value through migration background, AV $\mathrm{LABOR}=$ Adding value through mere labor, LEARN = Learning, EXCLUS = Exclusion . 
To generate the map in figure 3, we have chosen a two-dimensional space solution in advance, because we are more interested in the associations between the considered variables and less in the latent structures. The two dimensions account for a similar proportion of total inertia (dimension 1: $55.0 \%$; dimension 2: $45.5 \%$ ). Compared with the map in figure 2, four aspects are of special interest: first, the diversity strategies Anti-discrimination, Learning, and Adding value through migration background now form a tight cluster. This cluster is strongly associated with the competitive strategy differentiation and is clearly separated from the diversity strategy Adding value through mere labor. Second, Exclusion is now also clearly separated from the other diversity strategies and manifestly related to both the competitive strategy cost leadership and to small companies (up to 50 employees). Third, the point representing the competitive strategy focus has shifted upwards and is now situated next to the point which represents the diversity strategy Adding value through mere labor. Finally, a look on the axes reveals that dimension 1 still is shaped by the diversity strategies, whereas the company size also spreads over dimension 2 .

All described differences between the maps in figure 3 and figure 2 can be interpreted as moderating effects. This means that the company size obviously shapes some relationships between diversity and competitive strategies. In particular, the association between the competitive strategy focus and the diversity strategies changed through the consideration of the company size; in the bivariate map, a focus strategy was most strongly related to the diversity strategy Adding value through migration background. In contrast, the consideration of the company size revealed the strongest relation to Adding value through mere labor. This shift can be traced back to the fact that a focus strategy is pursued more often by small and medium sized companies than by large ones.

Again, both an inspection of the underlying three-way contingency table and sensitivity analyses confirmed these results. Hence, altogether we conclude that proposition 3 is supported.

\section{Proposition 4: Moderating effect of the industrial sector}

Analogous to proposition 3, we now investigate the moderating effect of the industrial sector $^{6}$ on the relationships between the diversity and the competitive strategies. Figure 4 displays the respective map.

Again, compared with figure 2, several changes can be identified. Some of them are quite similar to those triggered by the company size: the cluster that formerly consisted of the diversity strategies Anti-discrimination, Learning and Adding value through migration background is now enlarged by the strategy Adding value through mere labor. While

6 The sectors have been classified according to NACE as follows: Manufacturing basic = D 15-29; Manufacturing complex \& energy/water = D 30-36, E 40-41; Construction = F 45; Motor vehicles = G 50; Trade = G 51-52; Hotels $/$ restaurants \& transport $/ \mathrm{com}$ munications = H 55, I 60-64; Research/development \& IT = K 72-73; Advertising = K 743; Security \& building cleaning $=$ K 7492-7493; Health \& social work $=$ N 85; Culture, sports, \& entertainment $=$ O 92; Further services $=$ J 65-67, K 71, K 74 (except 743, 7492, 7493), O 91, O 93. 
these four diversity strategies are situated next to the competitive strategy differentiation, the points representing the diversity strategies Anti-discrimination and Learning are nearly fused. As a second change, the competitive strategy focus is now plainly separated from the other competitive and diversity strategies. Finally, the diversity strategy Exclusion again is clearly separated from the other diversity strategies and is still closely related to a cost leadership strategy. The two dimensions again account for fairly equal proportions of the total variance (dimension 1: $55.1 \%$; dimension 2: $49.5 \%$ ). The industrial sectors seem to be distributed across dimension 1 according to such characteristics as the prevalence of blue collar jobs and higher physical strain (left half) vs. white collar jobs and lower physical strain (right half). Moreover, this distribution seems to be associated with the location of the diversity strategy Exclusion and of the competitive strategy cost leadership (left half) vs. all other diversity strategies (right half).

Figure 4: Multiple correspondence analysis map - moderating effect of the industrial sector

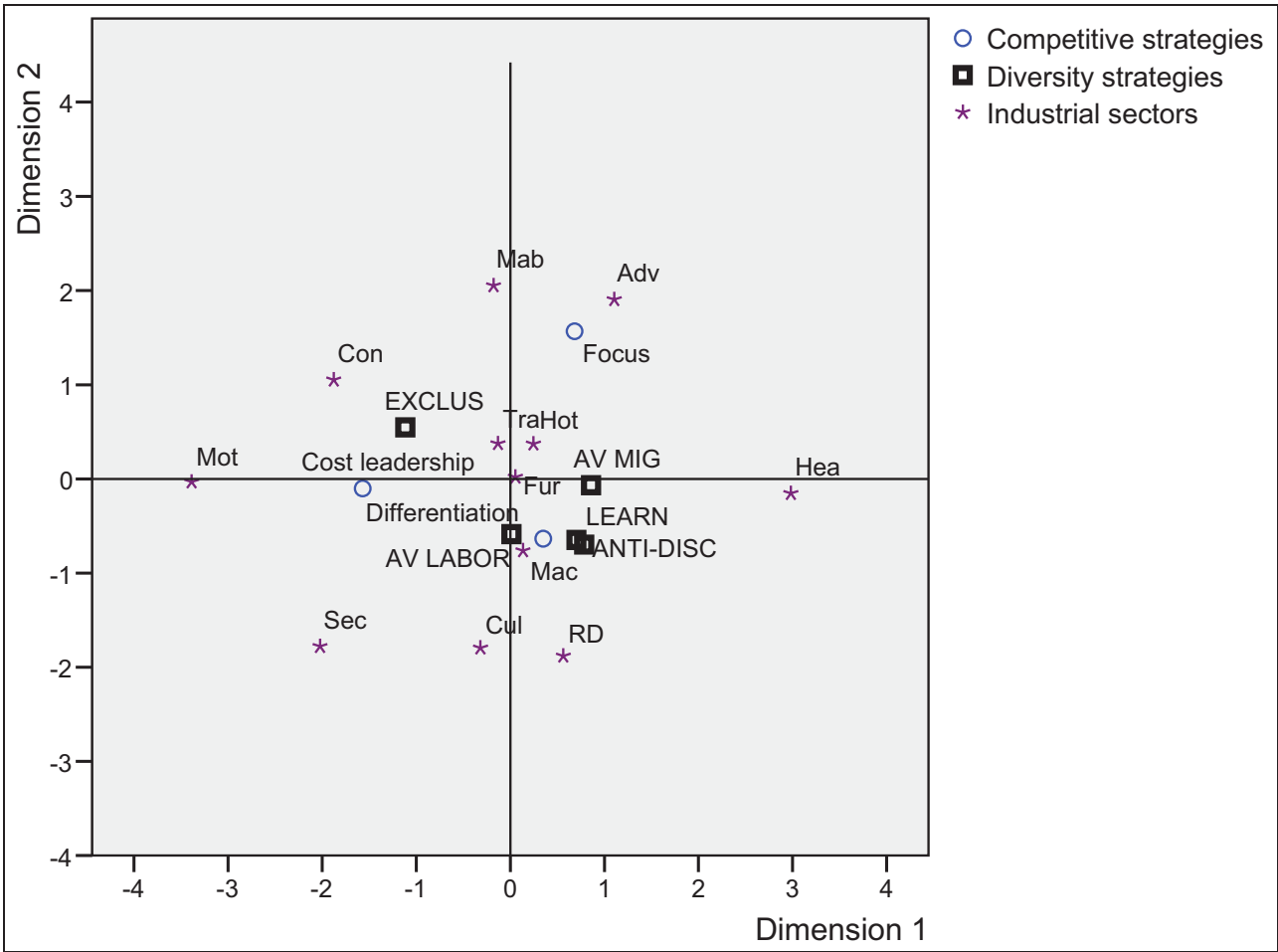

Notes: $\quad \mathrm{N}=239$; plot is based on $\mathrm{Chi}^{2}$-distances and symmetric normalization; Diversity strategies:

ANTI-DISC = Anti-discrimination, AV MIG = Adding value through migration background, AV LABOR = Adding value through mere labor, LEARN = Learning, EXCLUS = Exlusion; Industrial sectors: Mab = Manufacturing basic, Mac $=$ Manufacturing complex \& energy/water, Con = Construction, Mot = Motor vehicles, Tra $=$ Trade, Hot $=$ Hotels/restaurants \& transport/communications, RD = Research/development \& IT, Adv = Advertising, $\mathrm{Sec}=$ Security $\&$ building cleaning, Hea = Health \& social work, Cul = Culture, sports, \& entertainment, Fur $=$ Further services 
To summarize, we conclude that proposition 4 can also be supported. Again, contingency table (although with many empty cells and cells providing small frequencies) and sensitivity analysis did not reveal unexpected results.

\section{Further steps of analysis}

To complete the examination of our data, we carried out some further steps of analysis. We inspected another biplot of the diversity and competitive strategies complemented by both the company size and the industrial sector. The map did not change very much, except for the point representing the diversity strategy Adding value through migration background, which moved onto the points representing Anti-discrimination and Learning. The positioning of the diversity strategies Exclusion and Adding value through mere labor are quite stable.

Furthermore, we estimated multinomial regression models to determine both main effects and interaction effects of the considered covariates. However, presumably due to the comparatively small sample size, the overall goodness of fit of the models proved to be rather weak and the coefficients were not statistically significant. Thus, we estimated a binary logistic regression model to reduce complexity. ${ }^{7}$ To generate the dichotomous diversity strategy variable, we grouped those diversity strategies which build on the quest to accrue resources through people with a migration background (i.e. Anti-discrimination, Adding value through migration background, Adding value through mere labor and Learning) into one strategy Inclusion and contrasted it with the strategy Exclusion. Even this coarser model (again made up by main and interaction effects) did not reveal significant coefficients.

\section{Discussion}

In this paper, we propose a typology of diversity strategies which builds on the question why organizational decision makers employ people with a migration background, or refuse to do so. Through the theoretically driven construction as well as through empirical observation we shed light on the whole spectrum, ranging from problemoriented to benefit-oriented approaches to the employment of people with a migration background. In the course of our theoretical foundation, we realized how enriching it is to reinterpret concepts and results gained from diversity research out of a resource dependence perspective. This approach enabled us to construct a suitable typology of diversity strategies which build on one single, systematic answer to the question why people with a migration background are (not) employed. That is, which diversity strategy is chosen depends on the intent to accrue critical resources and to reduce dependencies on resource providers.

Moreover, we were able to demonstrate the robustness of our theoretically derived typology based on empirical data collected through telephone interviews with heads of personnel of 500 companies. Correspondence analyses exhibit the vigor of

Another way to reduce complexity would have been to merge some of the categories of the industrial sector variable. However, after the examination of various 3- and 4categories solutions, we rejected this approach. The variance within the categories nearly equalled the variance between the categories. 
our typology and support further propositions as to the relation of diversity and competitive strategies.

In summarizing the results as to proposition 1, we were able to identify all six diversity strategies based on our empirical data. It is striking that - besides the strategy Hazard - above all those strategies which are least favourable for people with a migation background themselves, i.e. Exclusion and Adding value through mere labor, are quite prevalent in the companies surveyed. Particularly an Exclusion strategy is more often than not empirically related to the competitive strategy cost leadership - as suggested within our second set of propositions. The further diversity strategies which build on the quest to accrue resources through people with a migration background, i.e., Antidiscrimination, Adding value through migration background, and Learning, could also be discerned. Additionally, and once more referring to proposition 2, we found that they are empirically related to a differentiation strategy. Here, presumably the resources which may be accrued through the employment of people with a migration background are evaluated to sustain the quest for high quality, innovative processes and products.

Moreover, both the company's size and the industrial sector to which it belongs affect the relationship between diversity and competitive strategies, a finding that supports our propositions 3 and 4. The consideration of the moderating variables changed the correspondence analysis maps, and these changes seem to be plausible in the light of our theoretical base. This is especially the case for the clustering of the three diversity strategies Anti-discrimination, Learning, and Adding value through migration background, because these are the strategies which strongly reflect that organizational decision makers ascribe unique qualifications or individual characteristics to people with a migration background. Interestingly, the consideration of moderating variables did not disturb the basic configuration of diversity and competitive strategies, indicating the robustness of our typology. Furthermore, in every correspondence analysis map the diversity strategies are aligned along the axis representing dimension 1 . This also reflects the strength of our typology: if the typology were less solid, the diversity strategies would sometimes get mixed up. In particular, the point representing the diversity strategy Exclusion always lies far away from the other diversity strategies and never in between. On the whole, our empirical findings endorse our theoretically derived typology of diversity strategies.

At this point, it would be intriguing to shed more light on the interplay of diversity strategies with personnel practices and personnel structures, that is, to dig more deeply into the actual configurations of the respective employment strategies. In order to illuminate such aspects, a qualitative approach would be appropriate. Another question which we masked out due to our empirical approach is which resources needed by the organization do employees or applicants with a migration background actually control. By virtue of our resource dependence perspective, we assume that the concurrence of resource control and the quest to accrue critical resources is accompanied and molded by power relations, by their establishment, enforcement, and change. However, these processes were not the focus of our study. These aspects demand a consecutive qualitative approach which would promise enriching insights.

A further question raised by our empirical approach is how validly we measured the proportion of people with a migration background. We can neither be sure that 
respondents know the exact number of respective employees nor if they under- or overestimate the proportion, for instance, due to supposed signals like names or skin color which do not automatically indicate the existence or absence of a migration background. However, we presume that our data set is large enough to average out errors based on such biases.

Finally, one might regard the measurement of all our constructs by subjective evaluations as suffering from a lack of methodological rigor. However, precisely this approach corresponds to our understanding of strategies and their choice and legitimation through resource dependencies. In this regard, we would like to emphazize that, by this approach to our research question, we neither propose nor pursue a rationalist strategy analysis as has been critized by many writers (see, for example, Smircich/Stubbart 1985; Ezzamel/Willmott 2008). That is, we do not aim to discover the "real demands and real constraints that (...) exist "out there" (Smircich/Stubbart 1985: 726) and to explore the best fit between the organization and its environment. Rather, the argument is based on the premise that a strategy's choice and legitimation results from evaluations of the criticality of resources and related conjectures about how to direct practices - in our case, about how to configure personnel practices and structures - in order to sustain and achieve competitive advantage.

Furthermore, with a special regard to resource dependence theory, researchers have discussed the adequacy of subjective versus objective or rationalist approaches. Do resources and their criticality have to actually exist and to be perceived to their correct extent? By no means is this the case, as Nienhüser (2004) also states: dependencies not only arise from material resources, but also from symbolic ones. Above all, individual as well as collective perceptions and attributions play a constitutive role an aspect that we judge as of particular significance for our aim to build insight into employment strategies related to people with a migration background.

\section{References}

Baker, T./Aldrich, H. E. (1999): The trouble with gurus: Responses to dependence and the emergence of employment practices in entrepreneurial firms. In: P. Reynolds (Ed.): Frontiers of Entrepreneurship Research 1999. Proceedings of the 19th Annual Entrepreneurship Research Conference. Wellesley, MA: Babson College: 1-14.

Barney, J. B. (2007): Gaining and sustaining competitive advantage. $3^{\text {rd }}$ ed. Upper Saddle River: Pearson.

Beck-Gernsheim, E. (2007): Wir und die Anderen. Kopftuch, Zwangsheirat und andere Missverständnisse [Us and them. Muslim headscarf, forced marriage and other misunderstandings]. Frankfurt a.M.: Suhrkamp.

Benzécri, J.-P. (1992): Correspondence analysis handbook. New York et al.: Dekker.

Bissels, S./Sackmann, S./Bissels, T. (2001): Kulturelle Vielfalt in Organisationen: Ein blinder Fleck muß sehen lernen [Cultural diversity in organizations: A blind spot has to learn how to look]. In: Soziale Welt, 52: 403-426.

Cox, T. H. Jr. (1993): Cultural diversity in organizations: Theory, research and practice. San Francisco: Berrett-Koehler.

Ely, R. J./Thomas, D. A. (2001): Cultural diversity at work. The effects of diversity perspectives on work group processes and outcomes. In: Administrative Science Quarterly, 46: 229-273.

Ezzamel, M./Willmott, H. (2008): Strategy as discourse in a global retailer: A supplement to rationalist and interpretive accounts. In: Organization Studies, 29: 191-217. 
Gaugler, E./Weber, W./Gille, G./Martin, A. (1985): Ausländerintegration in deutschen Industriebetrieben. Eine empirische Untersuchung über individuelle und soziale Integration [Integration of foreigners in German industrial plants. An empirical investigation on individual and social integration]. Königstein/Taunus: Athenäum.

Grant, R. M. (2005): Contemporary strategy analysis. $5^{\text {th }}$ ed. Malden et al.: Blackwell.

Greenacre, M. (1994): Correspondence analysis and its interpretation. In: M. Greenacre/J. Blasius (Eds.): Correspondence analysis in the social sciences. Recent developments and applications. London et al.: Academic Press: 3-22.

Greenacre, M./Blasius, J. (Eds.) (1994): Correspondence analysis in the social sciences. Recent developments and applications. London et al.: Academic Press.

Hair, J. F./Black, W. C./Babin, B. J./Anderson, R. E./Tatham, R. L. (2006): Multivariate data analysis. $6^{\text {th }}$ ed. Upper Saddle River, NJ: Pearson Prentice Hall.

Horwitz, S. K./Horwitz, I. B. (2007): The effects of team diversity on team outcomes: A meta-analytic review of team demography. In: Journal of Management, 33: 987-1015.

Janssens, M./Zanoni, P. (2005): Many diversities for many services: Theorizing diversity (management) in service companies. In: Human Relations, 58: 311-340.

Kochan, T./Bezrukova, K./Ely, R./Jackson, S./Joshi, A./Jehn, K./Leonard, J./Levine, D./Thomas, D. (2003): The effects of diversity on business performance: Report of the diversity research network. In: Human Resource Management, 42: 3-21.

Krell, G. (2008): Diversity Management - Chancengleichheit für alle und auch als Wettbewerbsfaktor [Diversty Management - equal opportunities for all and also as a competitive factor]. In: G. Krell (Ed.): Chancengleichheit durch Personalpolitik. Gleichstellung von Männern und Frauen in Unternehmen und Verwaltungen. Rechtliche Regelungen - Problemanalysen - Lösungen. $5^{\text {th }}$ ed. Wiesbaden: Gabler: 63-80.

Lutz, B. (1987): Arbeitsmarktstruktur und betriebliche Arbeitskräftestrategie. Eine theoretisch-historische Skizze zur Entstehung betriebszentrierter Arbeitsmarktsegmentation [Labor market structure and workforce strategy. A theoretical and historical outline of the emergence of internal labor market segmentation]. Frankfurt a.M. \& New York: Campus.

Martin, A. (1991): Statusabgrenzung gegenüber ausländischen Arbeitnehmern [Distinction from foreign employees]. In: Die Betriebswirtschaft, 51: 629-647.

Milliken, F. J./Martins, L. L./Morgan, H. (1998): Explaining organizational responsiveness to workfamily issues: The role of human resource executives as issue interpreters. In: Academy of Management Journal, 41: 580-592.

Mintzberg, H. (1978): Patterns in strategy formation. In: Management Science, 24: 934-948.

Mintzberg, H./Waters, J. A. (1985): Of strategies, deliberate and emergent. In: Strategic Management Journal, 6: 257-272.

Nenadić, O. (2007): An implementation of correspondence analysis in $\mathrm{R}$ and its application in the analysis of web usage. Göttingen: Cuvillier.

Nienhüser, W. (2004): Die Resource-Dependence-Theorie: Wie (gut) erklärt sie Unternehmensverhalten? [Resource dependence theory: How (good) does it explain organizational behavior?]. In: M. Festing/A. Martin/W. Mayrhofer/W. Nienhüser (Eds.): Personaltheorie als Beitrag zur Theorie der Unternehmung. München/Mering: Hampp: 87-119.

Nienhüser, W. (2007): Betriebliche Beschäftigungsstrategien und atypische Arbeitsverhältnisse. Eine Erklärungsskizze aus Sicht einer politischen Personalökonomik [Organizational employment strategies and atypical employment. Explication outline from a perspective of political personnel economics]. In: B. Keller/H. Seifert (Eds.): Atypische Beschäftigung - Flexibilisierung und soziale Risiken. Berlin: Edition Sigma: 45-65.

Nkomo, S. M./Cox, T. (1990): Diverse identities in organizations. In: S. R. Clegg/C. Hardy/W. R. Nord (Eds.): Handbook of organization studies. London: Sage: 338-356.

Ortlieb, R./Sieben, B. (2008): Exclusion, hazard, adding value, or learning? Diversity strategies focused on employees with a migration background. In: G. T. Solomon (Ed.): Best papers proceedings of the sixty-seventh annual meeting of the Academy of Management (CD), ISSN 1543-8643 (forthcoming). 
Pfeffer, J./Cohen, Y. (1984): Determinants of internal labour markets in organizations. In: Administrative Science Quarterly, 29: 550-572.

Pfeffer, J./Davis-Blake, A. (1987): Understanding organizational wage structure: A resource dependence approach. In: Academy of Management Journal, 30: 437-455.

Pfeffer, J./Salancik, G. R. (1978): The external control of organizations. A resource dependence perspective. New York et al.: Harper \& Row.

Porter, M. (1980): Competitive strategy: Techniques for analyzing industries and competitors. New York: Free Press.

Proudford, K. L./Nkomo, S. (2006): Race and ethnicity in organizations. In: A. M. Konrad/P. Prasad/J. Pringle (Eds.): Handbook of workplace diversity. London et al.: Sage: 323-344.

Richard, O. C. (2000): Racial diversity, business strategy, and firm performance: A resource-based view. In: Academy of Management Journal, 43: 164-177.

Sackmann, S./Bissels, S./Bissels, T. (2002): Kulturelle Vielfalt in Organisationen: Ansätze zum Umgang mit einem vernachlässigten Thema in den Organisationswissenschaften [Cultural diversity in organizations: Approaches to deal with a neglected topic in organization sciences]. In: Die Betriebswirtschaft, 62: 43-58.

Schuler, R. S./Jackson, S. E. (1987): Linking competitive strategies with human resource management practices. In: Academy of Management Executive, 1 (3): 207-219.

Smircich, L./Stubbart, C. (1985): Strategic management in an enacted world. In: Academy of Management Review, 10 (4): 724-736.

Thomas, D. A./Ely, R. J. (1996): Making differences matter: A new paradigm for Managing Diversity. In: Harvard Business Review, 74(6): 79-90.

Thomas, R. R. Jr. (1996): Redefining diversity. New York: Amacom.

Weber, I. (2004): Arbeitnehmer, ausländische [Employees, foreign]. In: E. Gaugler/W. A. Oechsler/W. Weber (Eds.): Handwörterbuch des Personalwesens. $3^{\text {td }}$ ed.. Stuttgart: Schäffer-Poeschel: 93-103. 